\title{
ТРАНСФОРМАЦИЯ ЭНДОВИДЕОХИРУРГИЧЕСКИХ МЕТОДИК ПРИ ОПЕРАТИВНЫХ УРОЛОГИЧЕСКИХ ВМЕШАТЕЛЬСТВАХ (ЛИТЕРАТУРНЫЙ ОБЗОР)
}

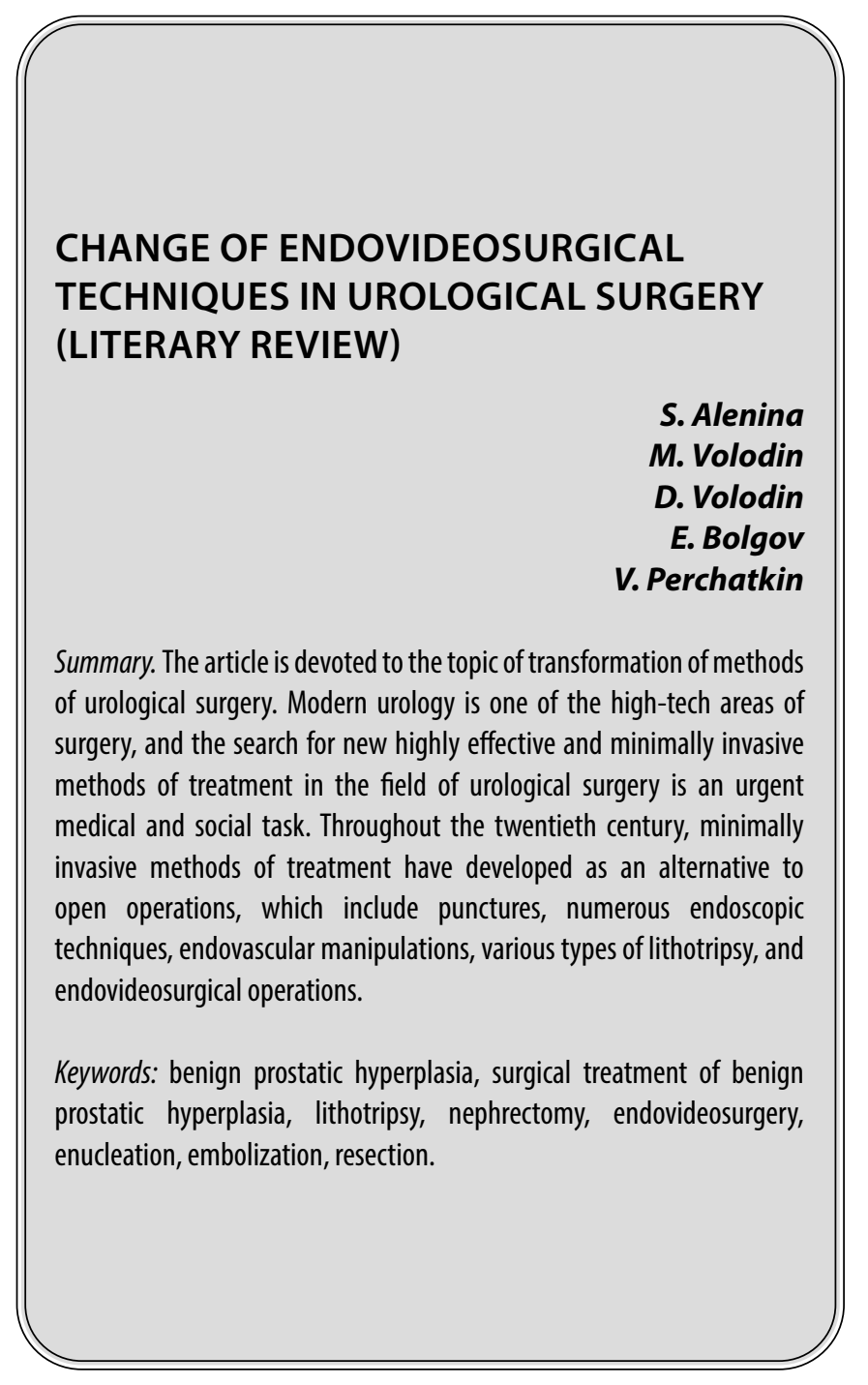

\section{Ввемение}

$\mathbf{y}$ рология как отдельное направление медицины зародилось за много веков до нашей эры еще в античном мире и развивалась вместе с обществом. Уровень ее развития имел характерные для каждого периода становления цивилизации черты, определяясь мировоззрением общества и состоянием науки в данный исторический период [23].

Первые свидетельства об урологических заболеваниях датируются несколькими тысячелетиями до нашей
Аленина Светлана Игоревна

ФГБОУ ВО ПИМУ Минздрава России, г. Нижний

Новгород

Володин Марк Альбертович

Aспирант, ФГБОУ ВО ПИМУ Минздрава России,

2. Нижний Новгород

Володин Денис Игоревич

Аспирант, ФГБОУ ВО ПИМУ Минздрава России,

2. Нижний Новгород

Болгов Евгений Николаевич

АНМО «Ставропольский краевой клинический консультативно-диагностический центр»,

г. Ставрополь

peregal@yandex.ru

Перчаткин Владимир Александрович

Врач-уролог, ГАУЗ «Городская клиническая больнича № 7», г. Казань

Аннотация. Статья посвящена теме трансформации методик урологических оперативных вмешательств. Современная урология представляет собой одну из высокотехнологичных областей хирургии, а поиск новых высокоэффективных и малоинвазивных методов лечения в области хирургических урологических вмешательств является актуальной медицинской и социальной задачей. На протяжении всего XX века в качестве альтернативы открытым операциям были разработаны малоинвазивные методы лечения, к которым можно отнести пункции, многочисленные эндоскопические методики, эндоваскулярные манипуляции, различные варианты литотрипсии, эндовидеохирургические операции.

Ключевые слова: доброкачественная гиперплазия предстательной железы, хирургическое лечение доброкачественной гиперплазией предстательной железы, литотрипсия, нефроэктомия, эндовидеохирургия, энуклеация, эмболизация, резекция.

эры, когда в древнеегипетских мумиях были обнаружены камни мочевого пузыря. Авиценной описаны операции камнесечения, разработана техника катетеризации мочевого пузыря. Francesco Pajola (1742-1816) из Венеции считается пионером литотомии. Широкое внедрение цистоскопии и катетеризации мочеточников заставило задуматься о возможности эндоскопического лечения урологических заболеваний.

В 1895 году В.К. Рентген открыл Х-лучи, и таким образом в руках врачей оказался новый, чрезвычайно важный диагностический инструмент. Enrico Dormia (1928- 
2009) изобрел многобраншевый экстрактор камней мочеточников. Модель оказалась настолько удачной, что получила всеобщее признание и широкое распространение во всем мире. Л.А. Юткиным был сконструирован первый аппарат для электрогидравлической литотрипсии «Урат-1», аналоги которого до сих пор успешно применяются в урологической практике.

Сергей Петрович Федоров, выдающийся ученый и хирург, разработал новые операции - одномоментную чреспузырную аденомэктомию (1899), пиелотомию in situ, субкапсулярную нефрэктомию, косопоясничный разрез при операциях на почках; предложил новые хирургические инструменты (зажим Федорова на почечную ножку) [5].

В 1991 году R.W. Clayman (США) выполнил первую лапароскопическую нефрэктомию. Настоящим прорывом в этой области следует считать появление и широкое внедрение робота da Vinci - робототехнической хирургической системы, которая значительно улучшила технические возможности эндоскопических вмешательств и расширила круг выполняемых, таким образом, урологических операций [23].

К сожалению, многие урологические заболевания не могут быть излечены без применения тех или иных хирургических методов. Традиционные оперативные вмешательства сопровождаются тяжелым послеоперационным периодом и вынуждают больного человека надолго отказываться от работы, от привычной для него жизни. В связи с ростом продолжительности жизни неуклонно растет количество пожилых больных, возрастные особенности которых не позволяют выполнить им традиционные операции $[2,6,8,18]$. Развитие методик, базирующихся на открытиях в естествознании, изобретении и усовершенствовании оборудования и инструментов, позволяют выполнять хирургические вмешательства с помощью малоинвазивных методов, что снижает риск послеоперационных осложнений и, в конечном итоге, улучшает качество жизни пациентов, страдающих урологическими заболеваниями $[16,17,21]$.

\section{Аитотрипсия}

Уже в 1982 году в Мюнхене был установлен первый литотриптор НМ-2 для камней почек [13]. После этого экстракорпоральная ударно-волновая литотрипсия быстро распространилась по всему миру как революционная технология лечения мочевых камней $[32,36]$.

С целью уменьшения стоимости и болезненности процесса литотрипсии, многофункционального применения и легкости управления в аппаратах второго поколения технические усовершенствования были на- правлены на разработку иных принципов генерации ударных волн, фокусирования, прилегания и систем локализации, хотя спектр показаний оставался прежним, как и при Дорньер НМ-3. Интегрирование ударно-волновых генераторов с водяной подушкой (вместо громоздкой ванны) с рентгеновским столом сделало эти машины многофункциональными. У некоторых, так называемых «недорогих литотрипторов», обнаружились некоторые недостатки в отношении эффективности и управляемости аппаратов, хотя последующая доработка устранила данные дефекты $[47,48]$.

Между 1990 и 1992 годами большинство лидирующих компаний, производящих литотрипторы, стали разрабатывать или модифицировать уже существующие системы $[28,30]$.

В настоящее время производителями представляется 2 основных типа литотрипторов: ESWL-table (Siemens Modularis, Dornier Compact Delta и Sigma, Storz Modulith SLK, Wolf Piezolith 3000, Direx Nova Ultima, Medstone STS-T, HTM LithoDiamond). Такие системы могут быть привлекательны для небольших отделений $[34,48]$ и уро-литотрипторы с одной рентгеновской системой локализации, специально разработанные для урологического применения (PhillipsLithDiagnost, Lithostarmultiline, ModulithSLX). Однако эти машины имеют ограниченные возможности в плане диагностических исследований (рентгеновские снимки, урография). Данные машины в основном предназначены для крупных stone-центров, хотя они могут быть экономически оправданы в средне-размерных отделениях с достаточной эндоурологической нагрузкой $[32,33]$.

Контактная литотрипсия (КЛТ) - это фрагментация камней в мочевом пузыре, мочеточниках и почках, с помощью ряда инструментов, один из которых непосредственно имеет контакт с камнем в организме пациента. Данный метод позволяет дробить конкременты разной плотности в любом отделе мочевыводящей системы за счет источника энергии, который подводится к камню при помощи гибкого световода. Преимуществом является снижение риска повреждения здоровых тканей, окружающих камень, а также периода болевых ощущений после операции, следовательно, реабилитация после литотрипсии занимает меньше времени. Эффективность метода по разным источникам составляет до 95\% [13, 33].

Дистанционная литотрипсия (ДЛТ) - это один из нехирургических способов терапии мочекаменной болезни у человека. Суть такого раздробления камней в почках заключается в том, что они измельчаются без прямого контакта. Необходимый эффект достигается путем применения ударной волны. В свою очередь, контактная литотрипсия предусматривает прямое измель- 
чение камней с помощью лазерного луча, сжатого воздуха, ультразвука. Для измельчения или раздробления применяется специальный генератор ударных волн. Он создает ударные волны, повторяющиеся с определенной частотой. Данная операция относится к вмешательствам закрытого типа, за исключением дробления так называемых коралловидных камней. Внедрение в клиническую практику дистанционной литотрипсии (ДЛТ) изменило тактику лечения больных мочекаменной болезнью (МКБ), открыв эпоху малоинвазивного лечения. В 1955 году физик Л. А. Юткин опубликовал теорию электрогидравлического эффекта разрушения твердых тел в жидкой среде, которая явилась основой для создания первых дистанционных литотриптеров [15].

\section{Нефроэктомия}

На сегодняшний день нефрэктомия является общепризнанным методом лечения, как при заболеваниях почек, ведущих к утрате функции почки, так и новообразований почек. Также, в последние годы, в связи с развитием трансплантологии, растёт число донорских нефрэктомий [14]. Стремление снизить травматичность операций и развитие медицинской техники привели к появлению принципиально нового вида хирургических вмешательств - лапароскопической хирургии. История развития лапароскопических операций в урологии начинается с 1990 года, когда R.V. Clayman (1991) выполнил первую лапароскопическую нефрэктомию по поводу онкоцитомы почки [42]. После выполнения первой лапароскопической нефрэктомии, данный метод хирургического лечения получил быстрое развитие и всемирное распространение. В настоящее время лапароскопическая нефрэктомия является общемировым стандартом лечения, как новообразований почек, так и заболеваний, ведущих к утрате функции почки [1, 22].

Золотым стандартом в лечении локализованных и местнораспространенных форм рака почки является радикальная нефрэктомия. Впервые резекция почки была выполнена Crerny $(1887)[1,14]$. До недавнего времени основными показаниями для органосохраняющих операций по поводу почечноклеточного рака было двустороннее поражение почек, поражение единственной функционирующей почки [42]. Существует два способа выполнения операции по удалению почки: традиционный (открытый, радикальный) и лапароскопический [4, $13,45]$.

\section{ЭнАОСКОПИЯ}

На сегодняшний день урология занимается диагностикой и лечением заболеваний почек, мочеточников, мочевого пузыря, уретры, а также мужских половых органов. Несмотря на то, что урология считается разделом хирургии, врачу-урологу очень часто требуются знание и по педиатрии, гинекологии, а также целого ряда других медицинских специальностей. Идея эндоскопических вмешательств существенно изменила представление больных о хирургических вмешательствах и возможностях диагностики. Эндоскопия широко применяется для диагностики урологических заболеваний, начиная от заболеваний уретры, и заканчивая патологией почек и мочеточников. При этом этот вид диагностики характеризуется максимальной информативностью и минимальными неудобствами для больного, а также риском осложнений.

Первую в истории эндоскопию - осмотр внутренней полости организма с помощью специальных инструментов без разрушения этой полости - выполнил Гиппократ в III веке до н.э., описавший технику ректоскопии. Первая попытка визуализации полого органа человека, в обозримые исторические времена, связана с Филиппом Боццини, который в 1795 г. осмотрел полость матки и прямой кишки. Мочевой пузырь для осмотра менее доступен, чем матка и прямая кишка, и для выполнения первой в мире цистоскопии понадобилась еще четверть века. Практически до конца XIX века удобного для осмотра полостей организма инструмента изобретено так и не было. Только 2 октября 1877 года в Дрездене Мах Nitze на трупе продемонстрировал изобретенный им цистоскоп, с помощью этого инструмента многие годы выполнялась не только цистоскопия, но и другие эндоскопические исследования, в том числе и лапароскопия. Цистоскоп Nitze с небольшими изменениями используется нами до сих пор.

\section{Уретроскопия}

Уретриты у мужчин до настоящего времени остаются одними из самых распространенных заболеваний. Почти 40\% мужчин в разных возрастных группах имеют данную патологию [32]. Ирригационная уретроскопия дает возможность дифференцировать такие клинические формы уретрита, как передний (воспаление слизистой уретры от наружного отверстия мочеиспускательного канала до сфинктера уретры), задний (от сфинктера уретры до внутреннего отверстия мочеиспускательного канала) и тотальный (от наружного отверстия мочеиспускательного канала до внутреннего). Уретроскопия способствует удалению из органа экссудата, механической элиминации микроорганизмов, создает активную гиперемию слизистой оболочки, позитивно влияет на процессы регенерации эпителия уретры [10, 11, 12].

Среди рентгеновских методов диагностики в урологии большое значение имеют рентгеноконтрастные методы, когда перед исследованием больному вводится особое вещество, которое позволяет намного четче уви- 
деть врачу на рентгенограмме ту или иную патологию. С появлением УзИ, которому уже несколько десятков лет, диагностика многих заболеваний мочеполовой системы стала намного легче, и что очень важно, безопасной, так как УЗИ, наверное, является самым безопасным методом исследования. Появление компьютерной томографии и магнитно-резонансной томографии также сыграло большую роль в совершенствовании диагностики урологических заболеваний $[30,40]$.

\section{ЭнАови еохирургия}

В 1986 году в Японии была изобретена миниатюрная видеокамера, которая надевалась на окуляр эндоскопа, и появилась возможность перенести изображение на экран монитора, сделав доступным всей операционной бригаде. Появились, во-первых, «зрячие» ассистенты, во-вторых, возможность одновременного обучения большого количества специалистов. Это дало толчок для невероятно быстрого развития эндохирургии, которая за считанные годы сделала прыжок, сравнимый со столетием, и появилась новая технология - эндовидеохирургия (ЭВХ). ЭВХ-операций гораздо легче переносились больными, снизилось количество и тяжесть осложнений. Основной этап операции при этом выполняется в полном объеме по принятым в традиционной оперативной хирургии правилам. Отсутствие широкого разреза, хорошая видимость и неограниченные возможности сделали лапароскопическую хирургию чрезвычайно перспективной. Первая в России ЭВХ-урологическая операция уретролитотомия была выполнена только в 1996 году. Таким образом, на сегодня ЭВХ в урологии является хорошо развитой медицинской технологией, способной обеспечить выполнение любой урологической операции с лучшими результатами, чем открытым доступом [3].

\section{Энук^еация при $\triangle Г П \gg К$}

Гольмиевая лазерная энуклеация предстательной железы - это метод лечения доброкачественной гиперплазии предстательной железы, в основе которого лежит удаление гиперплазированной ткани с помощью лазерного излучения, формируемого кристаллом гольмия. Ткань железы не резецируется, а удаляется по ходу анатомической капсулы предстательной железы. Внедрение гольмиевой лазерной энуклеации простаты (HoLEP) в клиническую практику изменило структуру хирургического лечения пациентов с (ДГПЖ) больших и гигантских размеров, поскольку позволило целиком удалять аденомы объемом более $80 \mathrm{~cm}^{3}[37,39,43]$. За последние годы проведено значительное количество исследований, доказывающих высокую эффективность и безопасность HoLEP в лечении ДГПЖ [7, 38, 46]. Методика зарекомендовала себя как сравнительно безопасная и не уступающая по эффективности позадилонной аденомэктомии. Часто- та ложных рецидивов при ее проведении не превышает 5\%. Основным недостатком HoLEP является высокая сложность освоения и длительный срок обучения (более 60 операций) [29, 38]. В связи с этим продолжается поиск более совершенных лазерных энуклеирующих методик, как перспективных при удалении ДГПж больших размеров [43]. Определенный несомненный интерес представляет тулиевый лазер. Внедренная в клиническую практику в 2005 году тулиевая лазерная энуклеация, сегодня претендует на ведущие позиции при удалении аденомы больших размеров [35]. Тулиевая энуклеация позволяет больным быстрее вернуться к нормальному ритму жизни, не требует (как и любая эндоскопическая операция) установки страховых дренажей во время операции и значительно сокращает длительность госпитализации и реабилитации. Подобные обстоятельства позволяют считать тулиевую лазерную энуклеацию высокоэффективной малоинвазивной методикой лечения доброкачественной гиперплазии предстательной железы больших размеров (объемом более $80 \mathrm{~cm}^{3}$ ).

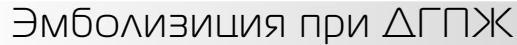

Продолжается поиск и совершенствование малоинвазивных методик оперативного лечения при доброкачественной гиперплазии предстательной железы (ДГПЖ). Один из новых методов лечения этого заболевания - эмболизация артерий простаты [41]. Достоинствами эндоваскулярных вмешательств являются: минимальная инвазивность, низкий операционный риск, быстрое восстановление пациентов, отсутствие необходимости в проведении анестезиологического пособия, возможность проведения у пожилых людей и у пациентов с тяжелой соматической патологией. Изначально эндоваскулярная эмболизация в урологии рассматривалась лишь как способ остановки жизнеугрожающих кровотечений из мочевого пузыря и предстательной железы $[27,44]$. У части пациентов после выполнения эмболизации в бассейне нижней мочепузырной артерии были отмечены редукция объема ПЖ и, как следствие, улучшение качества мочеиспускания, что натолкнуло исследователей на мысль о возможности применения данного метода в лечении больных ДГПЖ [27]. ЭПА зарекомендовала себя как самодостаточный метод лечения ДГПж, предоперационный метод перед выполнением ТУРП при крупных аденомах простаты, альтернативный хирургический метод лечения, позволяющий избежать таких осложнений, как ретроградная эякуляция, для лиц, желающих сохранить физиологичную и адекватную репродуктивную функцию [31]. На сегодняшний день эмболизация артерий простаты - один из немногих методов, которые можно применить у больных с тяжелыми сопутствующими заболеваниями. Это связано с его минимальной инвазивностью, т.е. наименьшим воздействием на организм при высокой эффективности. 


\section{Трансуретральная резекция при $\triangle \Gamma \sqcap \gg$}

Трансуретральная резекция предстательной железы (ТУР ПЖ) согласно клиническим рекомендациям Российской, Европейской и Американской ассоциаций урологов продолжает оставаться «золотым стандартом» в лечении ДГПЖ объемом до 80 см3.

Вмешательство является малоинвазивным, имеет небольшой период реабилитации, минимальное количество противопоказаний и побочных эффектов. После операции пациенты быстро восстанавливаются и могут вернуться к привычному образу жизни уже через несколько суток. В дальнейшем они не ограничиваются в физической и половой активности. Операция ТУР аденомы проводится без вскрытия полости мочевого пузыря. Благодаря этому снижаются риски инфицирования, сокращается время реабилитации пациента, устраняются риски возникновения осложнений. Целостность органа гарантирует быстрое восстановление процесса мочеиспускания. Если после открытой операции катетер удаляется только через несколько недель, то после ТУР — через пару дней.

\section{Биполярная трансуретральная резекция при $\triangle Г П \gg К$}

Значительный технический прогресс в ТУР был достигнут благодаря введению биполярной технологии. С момента появления в 1998 г. биполярной трансуретральной резекции у хирургов расширился арсенал методов электрохирургического лечения.

Комбинированная биполярная ТУР простаты является эффективным, малотравматичным и безопасным методом хирургического лечения у больных пожилого и старческого возраста.

Биполярная плазменная абляция создает надежный гемостаз с минимальными геморрагическими осложнениями. Биполярная ТУР аденомы простаты может быть успешно использована у больных раком простаты в качестве первого этапа перед дистанционной лучевой терапией.
Комбинированная биполярная ТУР в физиологическом растворе дает возможность работы без временных ограничений из-за риска развития ТУР-синдрома $[9,19,20]$.

\section{^азерная терапия \\ при му»жском бесп^оАии}

Лазерная терапия (ЛТ), активно развивающаяся в последние годы обладает ярко выраженными протекторными свойствами и демонстрирует высочайшую эффективность лечения во многих областях медицины, в том числе, в акушерстве и гинекологии, андрологии и урологии $[25,26]$, рекомендуется как составная часть комплексного решения проблемы бесплодия. Многие исследователи обращают внимание на то, что воздействие именно импульсным ИК НИЛИ с трансректальной доставкой энергии лазерного света предпочтительнее при лечении больных хроническим неспецифическим простатитом (ХНП). Варьирование частотой в зависимости от активности воспалительного процесса в предстательной железе позволяет индивидуализировать терапию больных ХНП и добиваться лучшей результативности $[24,27]$. Лазерная акупунктура [25] дополнительно увеличивает концентрацию и уменьшает число патологических форм сперматозоидов в эякуляте на 10-15\%, улучшая эндокринную регуляцию сперматогенеза. При этом достаточный терапевтический эффект достигается уже после выполнения 5 процедур.

\section{Выво $\triangle \mathrm{b}$}

Оперативная урология зародилась за много веков до нашей эры и продолжает развиваться вплоть до сегодняшних дней. В настоящее время урология представляет собой одну из высокотехнологичных областей хирургии благодаря оперативным возможностям урологов, имеющим в арсенале малоинвазивные методы лечения, такие как литотрипсия, нефроэктомия, эндовидеохирургические методики, энуклеация, эмболизация и резекция простаты при ДГПЖ. Развитие и создание новых вариантов лечения, трансформация хирургических методик и их использование позволяет минимизировать риск послеоперационных осложнений, тем самым повысить качество жизни мужчин, перенесших урологическое оперативное вмешательство.

\section{ЛИТЕРАТУРА}

1. Аболмасов А. В. Хирургия естественных отверстий — новая ступень развития лапароскопической хирургии // Материалы XV съезда общества эндохирургов России // Альманах института хирургии им. А. В. Вишневского. 2012. № 1. Т. 7. С. 416-417.

2. Аляев Ю.Г., Ахвледиани Н. Д., Левко А. А. Инновационные методы визуализации в урологии // Медицинский вестник Башкортостана. 2008. Т. 3. № 2. C. 22-27.

3. Антонов А. В. Эндовидеохирургия в урологии: терминология, история, показания, возможности, осложнения // Урологические ведомости. 2012. 2(1). C. $42-48$. 
4. Газимиев М. А. Неинвазивная диагностика обструктивных заболеваний мочевых путей: Дисс. на соискание ученой степени докт. мед. наук. М. 2004.

5. Гаспарян А. М., Ткачук В. Н. Роль С. П. Федорова в развитии отечественной урологии. Урология 1956; 3:3-7

6. Гаспарян А. М., Гаспарян С. А. , Ткачук ВН. Очерки по истории отечественной урологии. Медицина, Л.; 1971

7. Еникеев Д.В., Глыбочко П. В., Аляев Ю. Г., Рапопорт Л. М., Еникеев М. Э., Цариченко Д. Г., Сорокин Н. И., Суханов Р. Б., Дымов А. М., Хамраев О. Х., Давыдов Д.С., Тараткин M. С., Симбердеев Р. Р. Гольмиевая лазерная энуклеация (HOLEP) при гиперплазии простаты маленьких, больших и гигантских размеров. Практические рекомендации. Опыт более 450 операций. Урология. 2016. № 4. С. 63-69.

8. Калининская А.А., Машин А. Г., Севрюков Ф. А. Факторы риска развития гиперплазии предстательной железы // Социальные аспекты здоровья населения. 2013. T. 29. № 1. С. 1-9.

9. К Калининская А.А., Севрюков Ф. А. Современные возможности трансуретральной электрорезекции в физиологическом растворе в лечении заболеваний нижних мочевых путей и простаты // Международный журнал экспериментального образования. 2012. № 6. С. 41-43.

10. Лобкарев 0. А. Пути оптимизации эндоскопической диагностики и лечения заболеваний мужской уретры и предстательной железы: Дисс. на соискание ученой степени докт. мед. наук. Казань. 2005.

11. Лобкарев А. О. Материалы 80-й студенческой научной конференции КГМУ. Казань. 2006. С. 72-73.

12. Лобкарев А. О. Материалы научной конференции «Молодые ученые в медицине». Казань. 2006. С. 200-201.

13. Лопаткин Н.А., Дарепков А. Ф., и др. Урология. Москва.: Медицина, 1995. 297-348 с.

14. Одилов А.Ю., Кадыров 3. А., Колмаков А.С. Однопортовая лапароскопическая нефрэктомия // Вестник Авиценны. 2015. 2(63). ( $119-126$.

15. Руденко В. И. Современные аспекты клинической эффективности дистанционной литотрипсии // Урологические ведомости.— 2017.— Т. 7.— № 1S.— C. $93-95$.

16. Севрюков Ф. А. Комплексные медико-социальные и клинико-экономические аспекты профилактики и лечения доброкачественной гиперплазии предстательной железы: Автореф. дисс. докт. мед. наук. Москва, 2012.

17. Севрюков Ф.А., Камаев И. А., Гриб М. Н., Перевезенцев Е. А. Основные аспекты обеспечения высококвалифицированной урологической медицинской помощью больных с доброкачественной гиперплазией предстательной железы // Российский медико-биологический вестник имени академика И. П. Павлова.-2011. -Том 19. -№ 1. -С. 109-113.

18. Севрюков Ф.А., Камаев И. А., Малинина 0. Ю., Гриб М. Н., Перевезенцев Е. А. Социальный статус пациентов, страдающих доброкачественной гиперплазией предстательной железы // Общественное здоровье и здравоохранение. 2011. № 1. С. 53-56

19. Семенычев Д.В., Севрюков Ф. А., Сорокин Д. А., Карпухин И. В., Пучкин А. Б., Кочкин А. Д., Кнутов А. В. Сравнительная оценка биполярной трансуретральной вапорезекции (TUVRB) и биполярной резекции (TURIS) в лечении доброкачественной гиперплазии простаты // Медицинский вестник Башкортостана. 2015. T. 10. № 3. С. 16-19.

20. Сорокин Д.А., Семенычев Д. В., Володин М. А. Лечение и профилактика осложнений трансуретральных эндоскопических операций по поводу доброкачественной гиперплазии простаты // International Journal of Medicine and Psychology. 2019. Т. 2. № 4. С. 118-125.

21. Сорокин Д.А., Семенычев Д. В., Володин М. А. Гиалуроновая кислота в профилактике дизурических и обструктивных осложнений эндоскопических операций по поводу доброкачественной гиперплазии простаты // International Journal of Medicine and Psychology. 2019. Т. 2. № 3. С. 129-135.

22. Трапезникова М.Ф. Опухоли почек.-М., 1978. - 183 с.

23. Урология: учебник. Комяков Б. К. ГЭОТАР-Медиа 2012.- 464 с.: ил.

24. Юршин В. В. Комплексное лечение хронического простатита с использованием низкоэнергетического лазера: Автореф. дис. .. канд. мед. наук. М.; 1998.

25. Юршин В. В. Магнитолазерная терапия в лечении мужского бесплодия. Национальный медицинский каталог.- М.: Издательская группа «БДЦ-Пресс». 2003. № 2(3). С. 171-173.

26. Юршин В.В., Сергиенко Н. Ф., Илларионов В. Е. Этиопатогенетическое обоснование применения магнитолазерной терапии в комплексном лечении мужского бесплодия // Урология. 2003. № 2. С. 23-25.

27. Яковец Е.А., Неймарк А. И., Карпенко А. А., Яковец Я. В. Эмболизация артерий предстательной железы в лечении больных аденомой предстательной железы с высоким хирургическим риском // Андрология и генитальная хирургия. 2010. № 1. С. 38-43.

28. Baltaci S., Orach D., Soyupek S. Influence of tumor stage, size, grade, vascular involvement, histological cell type on multifocality of renal cell carcinoma // J. Urol.2000. - Vol.164. - P. 36-40.

29. Brunckhorst 0., Ahmed K., Nehikhare 0., Marra G., Challacombe B., Popert R. Evaluation of the Learning Curve for Holmium Laser Enucleation of the Prostate

30. Bueschen A.J., Lockhart M. E. Evolution of urological imaging // Int. J. Urol. 2011 . Vol.18 (2). P. 102-112.

31. Carnevale F.C., Antunes A. A., J. M. da Motta Leal Filho [et al.] Prostatic artery embolization as a primary treatment for benign prostatic hyperplasia: preliminary results in two patients // Cardiovasc. Intervent. Radiol. 2010. Vol. 33. P. 355-361.

32. Drach G.W., Dretler S. P., Fair W. R., Finlayson B., Gillenwater J., Griffith D. et al. Report of the United States cooperative study of extracorporeal shock wave lithotripsy. J Urol 1986;135:1127-33.

33. Eisenberger F., Chaussy C., Wanner K. Extrakorporale Anwendung von hochenergetischen Stosswellen. Ein neuer Aspekt in der Behandlung des Harnsteinleidens. Akt Urol 1977;8:3-15

34. Eisenberger F., Fuchs G., Miller K., Bub P., Rassweiler J. Extracorporeal shockwave lithotripsy (ESWL) and endourology: an ideal combination for the treatment of kidney stones. World J Urol 1985;3:41-7.

35. Fried N.M., Murray K. E. High-power thulium fiber laser ablation of urinary tissues at 1.94 microm. J Endourol. 2005; 19(1): $25-31$.

36. Fuchs G.J., Miller K., Rassweiler J., Eisenberger F. Extracorporeal shock wave lithotripsy: one year's experience with the Dornier lithotripter. Eur Urol 1985;11:145-9 
37. Gravas S.B.T., Bachmann A, Drake M, Gacci M, Gratzke C, et al. Management of Non-Neurogenic Male Lower Urinary Tract Symptoms (LUTS), incl. Benign Prostatic Obstruction (BPO) // EAU Guidelines on. Eur Assoc Urol. 叉2016.

38. Krambeck A.E., Handa S. E., Lingeman J. E. Holmium laser enucleation of the prostate for prostates larger than 175 grams. J Endourol. 2010 Mar;24(3):433-7. doi:10.1089/end.2009.0147

39. Kuntz R.M., Lehrich K., Ahyai S. A. Holmium laser enucleation of the prostate versus open prostatectomy for prostates greater than 100 grams: 5 -year follow-up results of a randomised clinical trial. Eur Urol 2008; 53(1): 160

40. Lamki N., David R., Madewell J. E. Bladder diseases and imaging methods // Crit. Rev. Diagn. Imaging. 1989. Vol. 29 (1). P. $13-101$.

41. Lourenco T., Pickard R., Vale L.[et al.] Benign Prostatic Enlargement team. Minimally invasive treatments for benign prostatic enlargement: systematic review of randomised controlled trials // Br. Med. J. 2008. Vol. 337. P. 1662.

42. Narmada P. Laparoscopic nephrectomy for benign nonfunctioning kidneys /P. Narmada, N. P. Gupta, G. Gautam // J. Minim Access. Surg. — 2005.— V.1, № 4, P. 149-154. 2. Eskicorapci S. Y. Laparoscopic radical nephrectomy: the new gold standard surgical treatment for localized renal cell carcinoma /S.Y. Eskicorapci [et al.] // ScientificWorldJournal.— 2007. -V. 9, № 7.-P. 825-36.

43. Naspro R., Suardi N., Salonia A., Scattoni V., Guazzoni G., Colombo R., et al. Holmium laser enucleation of the prostate versus open prostatectomy for prostates $>70$ g: 24-month follow-up. Eur Urol. 2006; 50(3): 563-8.

44. Pisco J.M., Pinheiro L. C., Bilhim T. [et al.] Prostatic arterial embolization to treat benign prostatic hyperplasia / // J. Vasc. Interv. Radiol. 2011. Jan. Vol. 22 (1). P. 11-19.

45. Robson C. S. Radical nephrectomy for renal cell carcinoma // J. Urol. — 1963. — Vol.89. — P. 37-41.

46. Saredi G., Pirola G. M., Pacchetti A., Lovisolo J. A., Borroni G., Sembenini F., Marconi A. M. Evaluation of the learning curve for thulium laser enucleation of the prostate with the aid of a simulator tool but without tutoring: comparison of two surgeons with different levels of endoscopic experience. BMC Urol. 2015

47. Servadio C., Livine P., Winkler H. Extracorporeal shock wave litho-tripsy using a new compact and portable unit. J Urol 1988;139:685-8.

48. Zwergel U., Neisius D., Zwergel T., Kopper D., Ziegler M. Results and clinical management of extracorporeal piezoceramic lithotripsy (EPL) in 1,321 consecutive treatments. World J Urol 1987;5:213-9.

( Аленина Светлана Игоревна, Володин Марк Альбертович, Володин Денис Игоревич,
Болгов Евгений Николаевич ( peregal@yandex.ru ), Перчаткин Владимир Александрович.
Журнал «Современная наука: актуальные проблемы теории и практики»

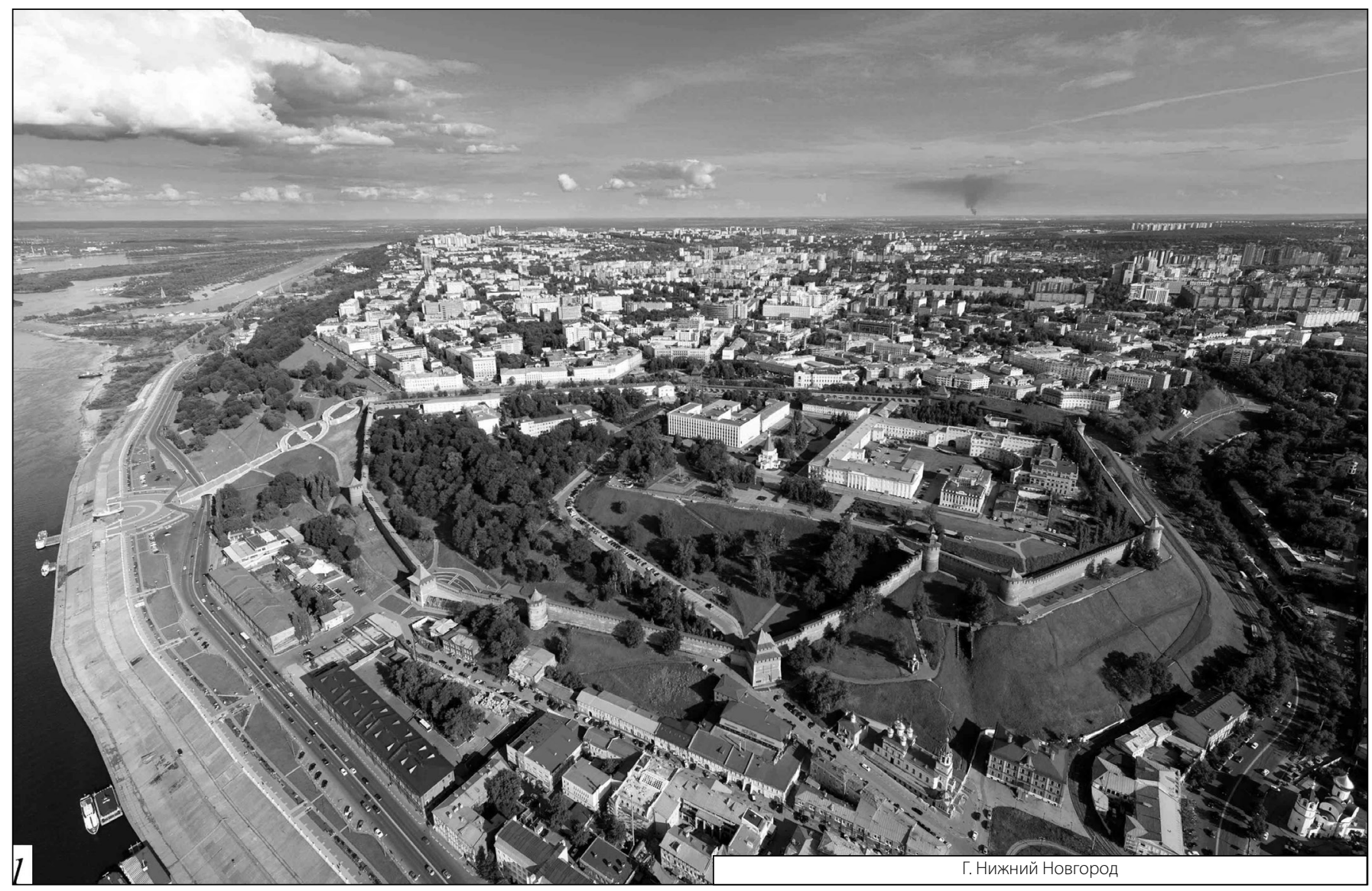

